\title{
EDUCAÇÃO SEXUAL NO CONTEXTO ESCOLAR: AS ESTRATÉGIAS UTILIZADAS EM SALA DE AULA PELOS EDUCADORES
}

\author{
N. S. Nogueira1* , A. R. Zocca2, L. R. Muzzeti² e P. R. M. Ribeiro² \\ ${ }^{1}$ Centro Universitário Central Paulista - UNICEP \\ ${ }^{2}$ Universidade Estadual Paulista - UNESP \\ nogueira.natty@gmail.com*
}

Artigo submetido em agosto/2014 e aceito em março/2016

DOI: $10.15628 /$ holos.2016.2302

\section{RESUMO}

A educação sexual é tema transversal em educação e consta nos Parâmetros Curriculares Nacionais (PCNs). Este artigo tem por objetivo compreender quais os materiais didáticos adotados no trabalho docente no esclarecimento dos questionamentos dos discentes em sala de aula. Participaram da pesquisa seis professores da educação de jovens adultos (EJA), entre 43 e 66 anos de idade, de uma cidade do interior do Estado de São Paulo. Os resultados mostraram que os professores conhecem os termos sexualidade e educação sexual e eles abordam a temática em sala de aula. Eles utilizam livros, filmes e diálogos na intervenção e destacam a importância da educação sexual na prevenção, quebra de tabus e conscientização dos alunos. Dessa forma, conclui-se que o trabalho sobre educação sexual na escola é relevante e pertinente, assim como, proporciona momentos de reflexões e aprendizados.

PALAVRAS-CHAVE: Professor, Material didático, Educação sexual.

\section{SEXUAL EDUCATION IN SCHOOL CONTEXT: THE STRATEGIES USED IN THE CLASSROOM FOR TEACHERS}

\begin{abstract}
Sexual education is a transversal theme in education and included in National Curricular Parameters (PCNs). This direction, the article aims to understand which learning materials on the subject to base teaching work in clarifying the questions of students in the classroom. Participated in the search six teachers of education of young adults, between 43 and 66 years old of a city in the state of São Paulo. The results showed that teachers
\end{abstract}

know the terms sexuality and sexual education and they speak sexuality in the classroom. They used books, movies and dialogues in action and highlight the importance of sexual education in the prevention, breaking taboos and awareness of the students. Therefore, sexual education in school is relevant and pertinent, as well as, provides moments of reflection and learning.

KEYWORDS: Teacher, Courseware, Sexual education. 


\section{INTRODUÇÃO}

O objetivo deste trabalho é compreender a utilização de materiais de apoio sobre sexualidade e educação sexual de professores da Educação de Jovens e Adultos (EJA). Neste sentido, a Lei de Diretrizes e Bases da Educação Nacional, número 9.394/96 estabeleceu no Art. 37 que "a educação de jovens e adultos será destinada àqueles que não tiveram acesso ou continuidade de estudos no ensino fundamental e médio na idade própria" (BRASIL, 1996). Portanto, aqueles que não conseguiram completar ou efetuar na idade regular os estudos podem concluí-los por meio do EJA.

Inicialmente é preciso esclarecer os significados de sexualidade e educação sexual. Segundo Maia e Ribeiro (2011) a sexualidade é um conceito amplo e histórico, representada de maneira diversa em cada cultura. Os componentes biológicos, psicológicos e sociais compõem a sexualidade que é expressa de maneira única em cada ser humano.

É um conceito amplo que abarca "um conjunto de fatos, sentimentos e percepções vinculados ao sexo, ou à vida sexual" (RIBEIRO, 2005, p. 17-18). Foucault (1988) contextualiza a sexualidade como um aparato histórico, uma "concepção social" criada por linguagem, procedimentos e instituições que se encontram em deliberado tempo e espaço histórico. Em outras palavras, a sexualidade é produzida ao longo da história.

A educação sexual, por sua vez, consiste no direito de toda pessoa de receber as informações sobre o corpo, a sexualidade e o relacionamento sexual, assim como, de expressar sentimentos, rever tabus, refletir e debater valores sobre tudo que está ligado ao sexo. Portanto, o papel da educação sexual formal na escola ultrapassa o ensino de conteúdos de biologia e fisiologia da sexualidade (FIGUEIRÓ, 2006, 2009).

Os professores, muitas vezes, não conversam com seus alunos pela falta de informações sobre a temática, por não conhecerem suficientemente o assunto ou não conseguem informar e/ou transmitir os conteúdos durante as aulas.

De acordo com Louro (1997) a sexualidade na escola independe da existência de uma disciplina de educação sexual, pois ela se expressa independentemente dos discursos em cada sujeito. Neste processo, o educador é responsável por formar, informar, debater, investigar, promover e refletir sobre vários temas, bem como possibilitar a ampliação do conhecimento do aluno a respeito das diferenças culturais e valores existentes nos vários grupos sociais.

Para que o programa de educação sexual alcance suas principais finalidades e propostas, é necessário que os professores aumentem sua confiança em si mesmos e conheça seu papel sexual. É essencial lidar com preconceitos, obter conhecimentos que abarquem as características biológicas, psicológicas, sociais, morais, políticas e as diversidades humanas.

Muitos professores se deparam com situações embaraçosas em sala de aula. Segundo Sayão (1997) o professor deve ser o mediador e o organizador do processo pedagógico, favorecendo um novo olhar sobre a situação, propondo outras fontes de informação e possibilitando ao aluno refletir sobre novas construções de pensamentos. De acordo com Braga (2009) é necessário o educador se preparar para o desafio por meio de cursos, grupos de estudos e atividades de capacitação. Assim como "[...] cabe a escola abordar os diversos pontos de vista, 
valores e crenças existente na sociedade para auxiliar o aluno a encontrar um ponto de referência por meio da reflexão [...]" (BRASIL, 1998, p. 121). A educação sexual se respalda nos Parâmetros Curriculares Nacionais (PCNs) que destaca a orientação sexual como um tema transversal e, trouxe a tona resultados de discussões que acontece há anos por via internacional através de Conferências, Congressos e Encontros de caráter político/científico.

Dessa forma as escolas brasileiras são encorajadas a olhar em seu planejamento pedagógico e refletir sobre sexualidade. Entretanto, sobre as aulas de Educação Sexual, Vitiello (1994) afirma que idealmente devem ser ministradas por meio de metodologias participativas e dialógicas, baseadas em uma realidade sociocultural, desenvolvida com criatividade, intimista e lúdica. Deste modo, levando em consideração todos esses aspectos, qual seria o material didático de apoio que o professor utilizaria no auxílio às questões sobre sexualidade e educação sexual? As aulas de biologia abarcam a anatômica do corpo, mas e os aspectos sociais e psicológicos, como trabalhar na sala de aula?

Segundo Schmitz (1993) o material de apoio é a ponte entre as palavras e a realidade efetiva. Tendo como essência a função de ajudar o educando a refletir, possibilitando o desenvolvimento de sua imaginação e sua capacidade de estabelecer coerências. É aproximar o aluno da realidade e auxiliá-lo a retirar dela o que contribui para sua aprendizagem.

Portanto, os materiais de apoio são importantes instrumentos e sua utilização contribui no processo de ensino e aprendizagem, mas é necessário que o professor estabeleça um propósito, procure aproveitar as possibilidades didáticas e esteja vigilante às demarcações que o material apresenta. Na medida em que o material didático atenda a aprendizagem na qual o aluno possa questionar/refletir, debater/dialogar, levantar hipóteses, experimentar, investigar, buscar respostas e não apenas absorver informações prontas e acabadas.

\section{MÉTODO}

A metodologia ocupa lugar central no interior das teorias e consiste no caminho do pensamento e a prática exercida na abordagem da realidade, portanto, ela inclui o método, as técnicas e a criatividade do pesquisador, ou seja, sua capacidade pessoal e sensibilidade (MINAYO, 2011). Segundo Gonçalves (2005), a metodologia científica é caracterizada pela ação metodológica que consiste em avaliar os métodos e identificar, ou não, suas limitações sobre a sua própria utilização.

Esta pesquisa é de natureza qualitativa e de cunho descritivo, ou seja, baseia-se no método que não emprega instrumental estatístico como base de análise do problema, pois não pretende medir ou numerar (RICHARDSON, 1989). Segundo Minayo (2011), a pesquisa qualitativa trabalha com o conjunto de fenômenos humanos e compreende a realidade social dos indivíduos que agem e pensam sobre suas ações, e interpretam essas ações dentro de sua realidade vivida.

O instrumento de coleta de dados foi constituído por um questionário com perguntas abertas, tendo participado dela seis professores, de ambos os sexos, com idades entre 43 e 66 anos, que lecionam na Educação de Jovens Adultos (EJA), em uma cidade localizada no interior do Estado de São Paulo. 


\section{RESULTADOS E DISCUSSÃO}

As respostas dos participantes foram analisadas a partir de três tópicos e são eles: 1 . Sexualidade, 2. Educação sexual e 3. Materiais didáticos.

No primeiro tópico "Sexualidade" os professores relacionaram o significado de sexualidade ao aspecto biológico, ou seja, a compreensão do conceito se restringe a definição sobre o que é sexo. Um aspecto citado é o tabu existente na sociedade ao retratar o tema e potencializa a falta de diálogo existente nos contextos familiar e escolar.

Algo existente na vida de todos os seres vivos, cada um a seu modo, mas todos têm. (Professora, 46 anos)

Ainda um tabu, um certo conservadorismo em relação à sexualidade. Muita "libertinagem" sem diálogos esclarecedores por parte da família e escola, daí o caos que assola a juventude: drogas, doenças DST e outros. (Professora, 46 anos)

Sexualidade é a forma de lidar com os aspectos sexuais na vida de cada um. (Professora, 43anos)

A sexualidade tem um significado relevante, visto que faz parte da natureza humana. (Professora, 506 anos)

Diferenciação de sexo, comportamento do ser humano, distinção sexual e o relacionamento. (Professora, 66 anos)

Sexualidade é o ato de dois indivíduos quanto ao desejo e sexo. (Professor, 39 anos)

A sexualidade inclui o sexo, mas também a afetividade, o carinho, o prazer, o amor, os gestos, a comunicação, a intimidade, os valores e as normas morais que cada cultura elabora sobre o comportamento sexual (FIGUEIRÓ, 2006). Segundo Nunes (2012) a sexualidade é confundida com a dimensão biológica, no entanto, o conceito é muito abrangente e remete-se a amplitude cultural histórica da ação humana.

Quando os alunos questionam sobre os temas gerais relacionados à sexualidade e ao sexo, os professores estabelecem a comunicação de modo que o aluno esclareça suas dúvidas e compreenda o que está sendo transmitido por meio de diálogos construtivos como relatado nas falas abaixo:

Explico da melhor maneira possível, sem nenhum constrangimento. Acredito que este assunto deva ser tratado com naturalidade e não como tabu. (Professora, 46 anos)

Naturalmente iniciamos diálogos sadios e esclarecimentos, sem vergonha de abordar certos assuntos e com palavras fáceis de entender. (Professora, 46 anos)

Explico sobre os temas usando os conhecimentos e materiais disponíveis e adaptando-os ao nível da classe. (Professora, 43 anos)

Eu relaciono essa questão por meio de contextos atuais, os quais se relacionam com a rotina deles. (Professora, 50 anos) 
Procuro responder com naturalidade e direta sem aprofundar. (Professora, 66 anos)

Eu de uma maneira bem natural explico o tema e quando não sei faço pesquisa e trago na aula seguinte. (Professor, 39 anos)

Ressalta-se que, o contexto escolar proporciona a reflexão da sexualidade por meio das dúvidas trazidas pelos alunos quando não existe planejamento para abordar o tema.

Para Guimarães (1995) a escola ainda se mostra tradicional e conservadora, impedindo, assim, que a "fala" seja feita de maneira tranquila e equilibrada, pois esse recinto ainda não se posiciona bem resolvida quanto a este assunto, cultivando a vergonha ao se "falar sobre sexo".

Portanto, a sexualidade deve ser abordada com naturalidade, pois é dessa maneira que ela se manifesta. Os temas devem ser colocados de acordo com os interesses dos alunos e atender às demandas pedagógicas, observando os valores ideológicos previamente introduzidos pela família e demais grupos sociais, bem como a faixa etária dos educandos (WEREBE, 1998).

No segundo tópico "Educação sexual", os participantes relatam que a educação sexual é necessária, e a transmissão do conhecimento sobre sexualidade perpassa pelo esclarecimento das dúvidas e da prevenção.

Uma educação que esclarece dúvidas sobre sexo, para que se possa compreender de maneira correta.

De extrema importância nos dias atuais, em todos os ensinos, pois a ignorância em relação à certas doenças ainda insistem em fazer parte da vida das pessoas. (Professora, 46 anos).

Importantíssimo, pois com educação as pessoas passam, a lidar com a sexualidade de forma mais responsável e saudável. (Professora, 43 anos)

Ela é importantíssima, uma vez que tem o objetivo de informar, instruir e orientar as pessoas nesse aspecto se faz necessário que ela exista. (Professora, 50 anos)

É uma forma de orientação com os alunos conhecer essa parte com mais naturalidade. (Professora, 66 anos)

A educação sexual é fundamental no ensino aprendizagem do aluno para instruílo nas dúvidas e na prevenção. (Professor, 39 anos)

Em relação à educação na escola, os professores disseram que:

Acho importantíssimo para acabar com tabus, prevenir doenças, gestações indesejáveis e até mesmo a homofobia. (Professora, 46 anos)

Extremamente importante!!!! Se a décadas atrás houvesse em sala de aula, talvez a adolescência seria mais saudável e menos doente. (Professora, 46 anos)

Penso que é de extrema importância e acho que deveria fazer parte da grade curricular. (Professora, 43 anos) 
Como citei anteriormente, a educação instrui e, também, contribui para o conhecimento significativo, principalmente, nessa área da convivência humana. (Professora, 50 anos)

Eu acho muito importante, pois os adolescentes estão iniciando a vida sexual muito cedo. (Professora, 66 anos)

Bem pouco. (Professor, 39 anos)

A educação sexual vem sendo reconhecida pela maioria dos professores como necessária no processo formativo dos alunos e conclui-se que, os participantes compreendem essa necessidade. Este é o primeiro passo para a efetivação da transmissão do conhecimento na sala de aula.

A educação sexual é o processo educativo na qual a pessoa adquire informações sobre sexo, sexualidade, corpo e gênero. E formam-se atitudes, valores e crenças sobre sexualidade (BENITES, 2006). Por isso, a iniciativa dos professores em refletir sobre o tema em sala de aula beneficia a construção do conhecimento para os alunos e retifica os benefícios da reflexão do tema.

O papel do professor que se dispõe a falar sobre sexualidade no espaço escolar seria de criar oportunidades de reflexão para que os alunos pensem e discutam com os colegas e formem sua própria opinião sobre sexo, masturbação, homossexualidade, aborto, etc., assim como, fazer com que os alunos tenham acesso às informações claras, objetivas e científicas sobre o tema (FIGUEIRÓ, 2009).

Para Sayão (1997), os programas de educação sexual deve se construir a partir de dúvidas trazidas pelos alunos e três eixos deveriam estruturar tal orientação e são eles, o corpo humano, as relações de gênero e a prevenção às DST e AIDS. Sendo assim, a participação dos alunos, trazendo perguntas e dialogando-as, pressupõe respeito ao conhecimento do professor, afetividade, confiança, relações abertas entre os educadores e educandos. De acordo com Werebe (1998) a escola desempenha um papel importante na educação sexual dos alunos independente das intervenções formais que ofereçam.

O material didático é necessário e auxilia o professor na abordagem dos temas sobre sexualidade em sala de aula. É por meio dele que o professor transmite os conteúdos aos seus alunos. No tópico 3 "Materiais didáticos", os professores relatam as estratégias utilizadas em sala de aula.

Os poucos materiais que são encontrados na escola, sobre esse assunto e alguns livros didáticos. (Professora, 46 anos)

Ás vezes o diálogo mesmo, mas em sala de aula preparada, filme e livros didáticos. (Professora, 46 anos)

Diálogos informais para que os tabus sobre os temas não prejudiquem o aprendizado que devem adquirir. (Professora, 43 anos)

A interação dialógica. (Professora, 50 anos)

Conforme a necessidade do assunto. (Professora, 66 anos) 
Sempre uma forma séria e direta, para que não se perca em brincadeira. (Professor, 39 anos)

E os métodos didáticos utilizados são:

Livros, pesquisas tiradas da internet, filmes, entre outros, dependendo da idade dos alunos. (Professora, 46 anos)

Livros, slides, filmes, depoimentos. (Professora, 46 anos)

Pesquisas em internet, livros didáticos e algumas campanhas disponibilizadas pelo governo. (Professora, 43 anos)

Não utilizo nenhum material específico. (Professora, 50 anos)

Não, porque não tem (talvez alguns textos) ou livros didáticos enfatizando o genital, gravidez, doenças. (Professora, 66 anos)

Xerox colorido do tema ou na lousa. (Professor, 39 anos)

Figueiró (2009) diz que ensinar sobre sexualidade na escola não se limita a colocar em prática, estratégias de ensino, mas envolve ensinar através da atitude do educador. De acordo com Furlani (2009) objetivo fundamental é contribuir para que alunos possam viver suas sexualidades de forma emancipatória, prazerosa e afetiva. E se propõe a trabalhar o respeito por si e pelo outro e garantir direitos básicos como a saúde, informação e o conhecimento, estes são elementos fundamentais para a formação de cidadãos responsáveis e conscientes de suas capacidades, direitos e deveres.

Segundo Silva e Ribeiro (2011) para refletir e argumentar a sexualidade e facilitar o ensino integrado e contextualizado é preciso vincular diversas formas pedagógicas de ensino e aprendizagem, não se acomodando apenas ao espaço escolar e seus objetos didáticos. E a partir dos relatos dos professores, o diálogo, os livros didáticos, filmes e slides são as estratégias e métodos utilizados no processo de ensino-aprendizagem e contribuiriam para auxiliá-los na transmissão do conhecimento.

Dentre as estratégias utilizadas pelos professores o diálogo é seu núcleo. Para Cordeiro (2010) a linguagem é estruturante da relação pedagógica e influência na aprendizagem dos estudantes.

A partir da formação cultural, as pessoas carregam uma gama de tabus, preconceitos e sentimentos, muitas vezes, negativos, em relação ao sexo e dificulta falar abertamente sobre ele. Assim, quando o professor se propõe educar sexualmente os alunos, há que se pensar, em oportunizar aos professores o reeducar-se sexualmente participando de estudos (FIGUEIRÓ, 2009).

Esse processo de autoconhecimento e aprendizagem é relevante, pois, segundo Barcelos et al. (1996, p. 151) "os educadores, em sua maioria, continuam tratando o assunto apenas nos aspectos biológicos, ou no máximo, convidam um palestrante médico para isso".

Por fim, como afirmam Silva e Carvalho (2005) às oportunidades de desenvolvimento profissional nunca se esgotam por isso o professor nunca dominará totalmente sua trajetória, necessitando buscar novos caminhos constantemente. 


\section{CONSIDERAÇÕES FINAIS}

A educação sexual na escola é tema relevante, pertinente e proporciona momentos de reflexões e aprendizados para os alunos e educadores. Apesar dos professores compreenderem a sexualidade como algo natural, porém ligada ao sexo, é que se propõe aprimoramentos fundamentais para a construção de novos saberes no âmbito da sexualidade e da educação sexual no contexto escolar.

Sendo assim, para o desenvolvimento da educação sexual podem ser utilizadas diferentes estratégias. Uma das mais citadas pelos professores é a utilização de materiais didáticos, mas é um fator limitante nas salas de aula, já que os professores relataram durante a pesquisa que há uma carência de materiais adequados. Neste sentido, problematizar a sexualidade nos espaços de formação de educadores e a elaboração de materiais didático-pedagógicos para que o trabalho da educação sexual se efetive nas escolas, devem ser colocados em pauta no âmbito das políticas públicas de formação e capacitação para a área da Educação.

Assim, considera-se pertinente a produção e distribuição de materiais didáticos que abordem alguns temas relacionados à sexualidade e que possam facilitar a abordagem desse tema.

Por fim, tem-se que, apesar dos professores apoiarem a educação sexual na escola, eles a consideram em um caráter preventivo. Dessa forma, percebe-se a necessidade de cursos de capacitação para os professores cujo objetivo seja aprofundar as temáticas da sexualidade e, consequentemente, proporcionar aos educadores maior respaldo nas explicações em sala de aula, e no aporte à materiais científicos sobre o tema.

\section{REFERÊNCIAS BIBLIOGRÁFICAS}

1. BARCELOS, N. S. et al. Educação sexual: relato de uma experiência. Revista Brasileira de Sexualidade Humana, São Paulo, v. 7, Edição especial n. 2, p. 150-160, 1996.

2. BENITES, M. J. de O. Educação sexual e formação docente: um estudo a partir de concepções discentes. 2006. Dissertação (Mestrado em Educação)-Universidade Regional de Blumenau, Blumenau, 2006.

3. BRAGA, E. R. M. Sexualidade Infantil: a importância da formação de professores (as) na questão de gênero. In: CARBELLO, S. R. C.; COMAR, S. R. (Org.). Educação no século XXI: Múltiplos desafios. Maringá: Eduem, 2009. p. 129-139.

4. BRASIL. Ministério da Educação. Secretaria de Educação Fundamental. Parâmetros Curriculares Nacionais: terceiro e quarto ciclos - apresentação dos temas transversais. Brasília: MEC/ SEF, 1998.

5. _. Lei no 9.394, de 20 de dezembro de 1996. Estabelece as diretrizes e bases da educação nacional. (Seção V Da Educação de Jovens e Adultos). Disponível em: <http://www.planalto.gov.br/ccivil_03/leis/L9394.htm>. Acesso em: 22 jun. 2013.

6. CORDEIRO, J. A relação pedagógica: a didática em ação. In: . Didática. 2. ed. São Paulo: Contexto, 2010. p. 97-116.

7. FIGUEIRÓ, M. N. D. Educação sexual: como ensinar no espaço da escola. Revista Linhas, Florianópolis, v. 7,n.1,p. 1-21 2006. Disponível em:< http://www.periodicos.udesc.br/index. 
php/linhas/article/view/1323/1132>. Acesso em: 21 maio 2015.

8. _ Educação sexual: como ensinar no espaço da escola. In: . (Org.). Educação sexual: múltiplos temas, compromisso comum. Londrina: UEL, 2009. p. 141-172.

9. FIGUEIRÓ, M.N. D. O professor como educador sexual: Interligando formação e atuação profissional. In: RIBEIRO, P. R. M. Sexualidade e educação: aproximações necessárias. São Paulo: Arte e Ciência, 2004. p. 115-151

10. FOUCAULT, M. História da sexualidade I: a vontade de saber. Tradução de Maria Therezada Costa Albuquerque e J. A Guilhon Albuquerque. 10. ed. Rio de Janeiro: Graal, 1988.

11. FURLANI, J. Encarar o desafio da Educação Sexual na escola. In: SANTOS, D. B. C; ARAÚJO, D. C. de. (Org.). Sexualidade. Curitiba: SEED, 2009. p. 37-48.

12. GONÇALVES, H. A. Manual de metodologia científica. São Paulo: Avercamp, 2005.

13. GUIMARÃES, I. Educação sexual na escola: mito ou realidade. Campinas SP: Mercado das Letras, 1995 (Coleções Dimensões da Sexualidade).

14. LOURO, G. L. Gênero, sexualidade e educação: uma perspectiva pós-estruturalista. 11 ed. Petrópolis, RJ: Vozes, 1997.

15. MAIA, A. C. B.; RIBEIRO, P.R.M. Educação sexual: princípios para ação. Doxa: Revista Brasileira de Psicologia e Educação, Araraquara, v. 15, n. 1, p. 75-84, 2011.

16. MINAYO, M. C. S. O desafio da pesquisa social. In: Pesquisa social: Teoria, método e criatividade. 30. ed. Petrópolis: Vozes, 2011.

17. NUNES, C. A. Política, sexualidade e educação. Revista Digital do Paideia, Ribeirão Preto, v. 3, n. 2, p. 4-17, Out. 2011 - Mar. 2012. Disponível em: <http://www.fae.unicamp.br/revista/in dex.php/rfe/article/view/2957/2626>. Acesso em: 18 mar. 2013.

18. RIBEIRO, P. R. M. Sexualidade também tem história: comportamentos e atitudes sexuais através dos tempos. In: MAIA, A. C. B; MAIA, A. F. (Org.). Sexualidade e infância. Bauru: Cecemca; Brasília: MEC/SEF, 2005. p. 17-32. (Cadernos CECEMCA, no 1).

19. RICHARDSON, R. J. Pesquisa social: métodos e técnicas. São Paulo: Atlas, 1989.

20. SAYÃO, Y. Orientação sexual na escola: os territórios possíveis e necessários. In: AQUINO, J. G. (Org.). Sexualidade na escola: alternativas teóricas e práticas. São Paulo: Summus, 1997. p. 107-118.

21. SCHMITZ, E. Fundamentos da didática. 7. ed. São Leopoldo: UNISINOS, 1993.

22. SILVA, B. O.; RIBEIRO, P. R. C. Sexualidade na sala de aula: tecendo aprendizagens a partir de um artefato pedagógico. Revistas Estudos Feministas. Florianópolis, v. 19, n. 2, p. 521-533, 2011. Disponível em: <http://www.scielo.br/pdf/ref/v19n2/v19n2a14.pdf> Acesso em: 15 abr. 2014.

23. SILVA, M. P.; CARVALHO, W. L. P. Desenvolvimento do conhecimento pedagógico do conteúdo de sexualidade na vivência das professoras. Revista Ciência \& Educação, Bauru, v. 11, n. 1, p. 73-82, 2005.

24. VITIELLO, N. Reprodução e sexualidade: Um manual para educadores. São Paulo: CEICH, 1994.

25. WEREBE, M. J. G. Sexualidade, política e educação. Campinas, SP: Editora: Autores Associados, 1998. 